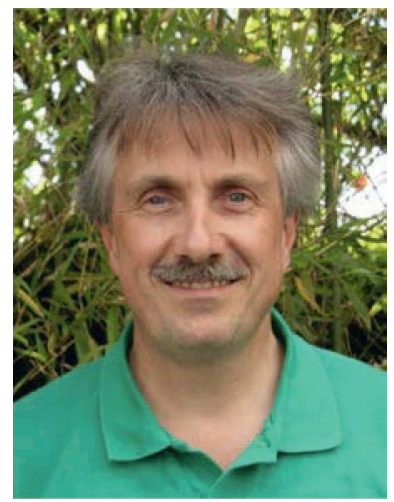

Thomas Pfister, Zürich, Schweiz

\section{Über die heilende Wirkung von Gärten}

Bereits im Alten Ägypten sollen Ärztinnen und Ärzte ihren Patienten Gartenspaziergänge verordnet haben, um deren Genesung zu beschleunigen. Obwohl Gärten in der Menschheitsgeschichte in erster Linie für die Produktion von Nahrungsmitteln angelegt wurden, erfüllen sie seit Langem auch eine andere Aufgabe: Sie dienen den Menschen als Aufenthalts- und Aktivitätsort. Von den alten chinesischen Kaisern bis hin zum «Sonnenkönig» Ludwig dem XIV. legten Herrscher prächtige Parks und Gärten an - natürlich auch zum Imponieren bei ihren Untergebenen und Konkurrenten. In der heutigen Zeit ist es eher der Staat, der vor allem in den zubetonierten Städten den stressgeplagten Bewohnerinnen und Bewohnern mit Grünflächen Erholungsmöglichkeiten bietet. Nachdem Schrebergärten etwas aus der Mode geraten sind, liegt nun «Urban Gardening» voll im Trend. Nicht mehr jede/r alleine im eigenen Gärtchen, sondern alle gemeinsam auf einem zugeteilten Grundstück nehmen Hacke und andere Geräte zur Hand und pflanzen Gemüse, Beeren und Kräuter. Vielerorts werden auch sogenannte «Interkulturelle Gärten» eröffnet, welche die Gelegenheit bieten, mit Menschen anderer Nationalität beim Gärtnern in Kontakt zu kommen.

Was im 19. Jahrhundert bereits im Rahmen der Reformpsychiatrie erfolgreich umgesetzt worden ist, wurde nach den Kriegen in Korea und Vietnam bei der Rehabilitation von kriegstraumatisierten Soldaten wiederentdeckt: die heilsame Wirkung der Gartenarbeit. Sowohl körper- liche als auch psychische Kriegsfolgen konnten mit der neu definierten Gartentherapie (horticultural therapy) wirksam gelindert oder sogar geheilt werden. In den 80er-Jahren des 20. Jahrhunderts wurden diese Erkenntnisse auf andere Zielgruppen wie Behinderte oder ältere Menschen übertragen und die Methoden entsprechend angepasst. Seit rund 20 Jahren werden nun auch im deutschsprachigen Raum gartentherapeutische Projekte durchgeführt. Im Altersbereich haben sich in vielen Einrichtungen Gartengruppen unter professioneller Leitung etabliert.

In der Gartentherapie können mit Ausnahme von Giftpflanzen fast alle Gewächse verwendet werden. Besonders beliebt und verbreitet ist der Anbau von Gemüse und Früchten, die in der Küche verwendet werden können. Vor allem älteren Menschen sind diese Pflanzen aus früherer Zeit bekannt und dienten zur Selbstversorgung. Mit einer Beschäftigung im Garten erhalten Menschen in Alterseinrichtungen die Möglichkeit einer sinnvollen Freizeitbeschäftigung. Mit Gartengruppen können zudem die Kontakte unter den älteren Menschen gefördert und der Tendenz zur Vereinsamung entgegengewirkt werden. Erste intergenerationelle Gartentherapie-Projekte sind erfolgreich erprobt worden.

Heil- und Küchenkräuter sind eine weitere Möglichkeit für therapeutisches Gärtnern. Viele dieser Pflanzen bieten vielfältige Sinneserfahrungen und sind einfach zu kultivieren. Sie können zudem für verschiedene Zwecke verwendet werden. Beliebt sind die verschiedenen Teekräuter wie z.B. Malven, Wegerich, Kamille usw. Im eigenen Garten gezogen, getrocknet und zu Teemischungen verarbeitet, können sie sowohl zum Genuss als auch zur Linderung von alltäglichen Beschwerden eingesetzt werden. Auch die Herstellung von Sirup, z.B. aus Zitronenmelisse und Minzen, ist sehr beliebt. Viele Küchenkräuter können entweder frisch für Salate, Kräuterbrote und Suppen verwendet oder getrocknet werden. Die getrockneten Kräuter sind lange haltbar und können beispielsweise für Kräutersalz verwendet werden. Auch Salben sind einfach in der Herstellung. So lässt sich aus Ringelblumenstrahlen unter Beigabe von Olivenöl, Bienenwachs und Lanolin ein Hautpflege-Balsam herstellen.

Mit den Heilkräutern aus dem eigenen Garten können somit zwei Effekte gleichzeitig erzielt werden: Zum einen fördert das Gärtnern die Beweglichkeit und die Fitness, zum anderen unterstützen die selber verarbeiteten Kräuter die Gesundheit und das Wohlbefinden.

\section{KARGER}

Fax +497614520714 Information@Karger.com www.karger.com
Thomas Pfister

Psychologe lic. phil., Gartentherapeut IGGT

Gartentherapie Pfister GmbH

Ackersteinstrasse 67, 8049 Zürich, Schweiz

thomas.pfister-adm@bluewin.ch

www.gartenundtherapie.ch 